A s i a $\mathrm{n}$ o u r nal of

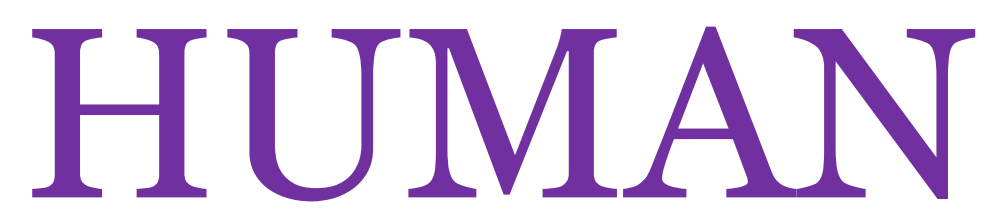

Printed 2018.1030 ISSN2188-059X

Published by Asian Society of Human Services

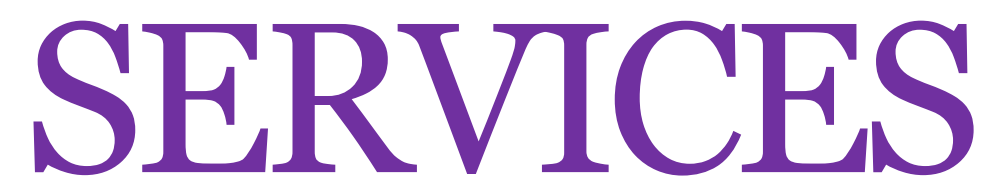

$\left.O_{\text {ctober } 2018}\right\rceil 5$
VOL.

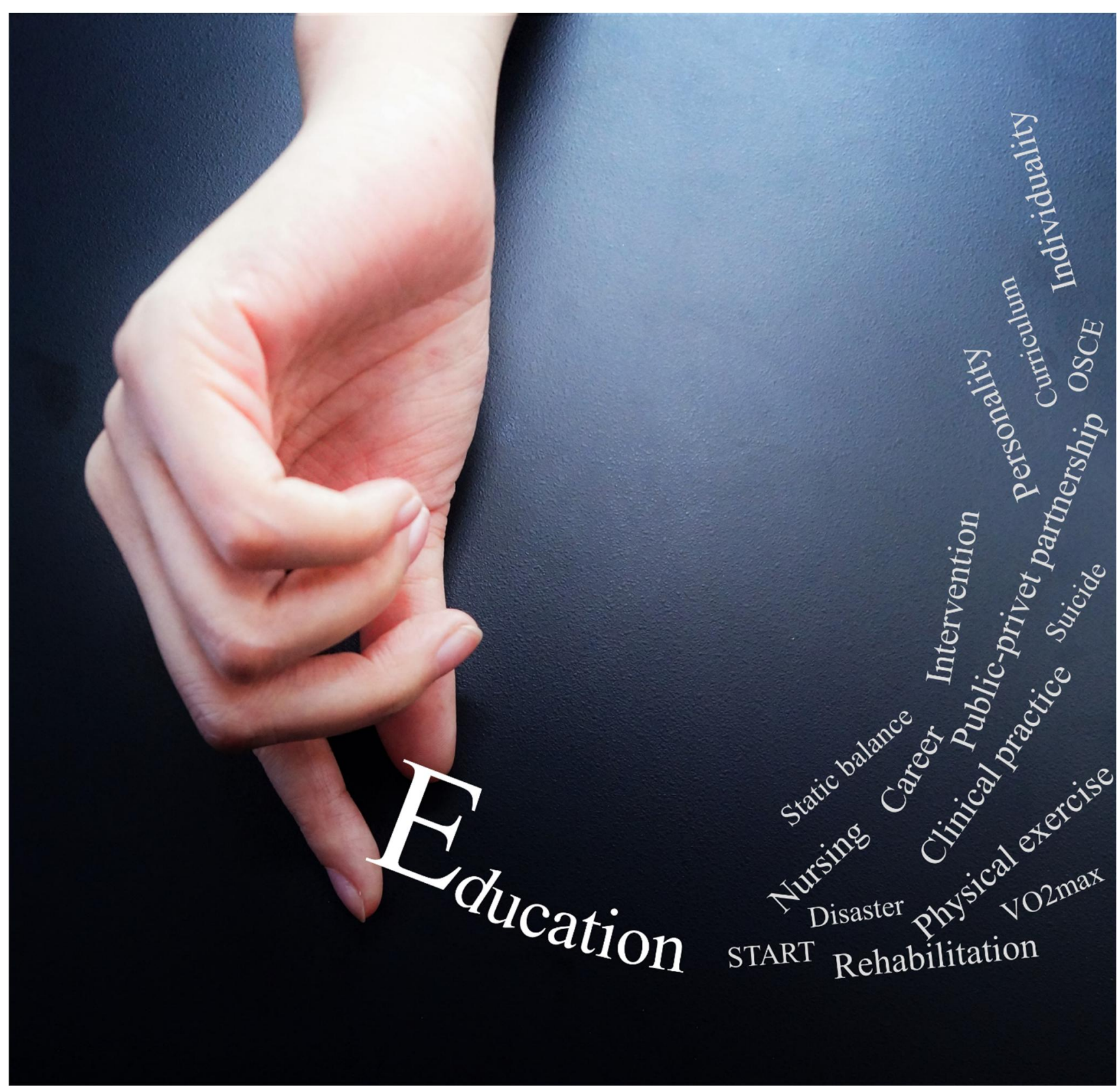




\title{
Services \\ Original Article \\ Effects of the OSCE to Motivate Students to Learn Before Clinical Practice
}

\author{
Yuko FUJIO 1) Shino SASAKI 1) Ryo HAYASHI 1) Junko ISHIZUKA 1) \\ Yasushi TAKEI 2) Takao OKADA ${ }^{3)}$
}

1) Faculty of Health Science and Nursing, Juntendo University, Japan

2) Health Science University, Japan

3) Department of Medical Education, Juntendo University School of Medicine, Japan

\begin{abstract}
Objective: The Objective Structured Clinical Examination (OSCE) as a common examination for medical and dental education was used for nursing education to examine its effects to enhance students' recognition of their learning goals and motivate them to learn before clinical practice. Methods: A self-administered questionnaire survey was conducted immediately after the OSCE. The questionnaire consisted of: goal achievement-related OSCE items; modified < attention>, < <elevance>, <confidence>, and $<$ satisfaction $>$ as the 4 key components of motivation in the ARCS model developed by John M. Keller; and free descriptions. Results: Among quantified scores from the ARCS model-based scale, those related to < satisfaction $>$ were the highest. <Satisfaction - the willingness to review $>$ also showed the highest standardizing coefficient in multiple regression analysis (stepwise method) of the items showing a strong correlation with the objective-related OSCE question: [Do you recognize your learning goals?]. The most frequent word contained in free descriptions was 'tension', which showed a tendency to co-occur with 'training' when examining linguistic networks. Conclusion: < Satisfaction the willingness to review> influenced the effect of the OSCE to motivate students to learn before clinical practice the most markedly. 'Tension' was suggested to be a psychological response of students.
\end{abstract}

Received

July 2, 2018

Revised

August 13, 2018

Accepted

August 19, 2018

Published

October 30, 2018

$<$ Key-words $>$

OSCE, clinical practice, effects to motivate students to learn

yfujio@juntendo.ac.jp (Yuko FUJIO; Japan) Asian J Human Services, 2018, 15:13-24. ㄷ 2018 Asian Society of Human Services 


\section{Introduction}

As a recent trend, an increased number of institutions providing healthcare education have adopted the Objective Structured Clinical Examination (OSCE). In medical and dental education, it has been formally adopted as a common examination to be taken by all students prior to clinical training since 2005 (Nakamura, 2014). In the literature on medical education, the OSCE has been reported to facilitate the evaluation of psychomotor (skills) and emotional (attitudes) domains, in addition to cognitive (knowledge) areas, and be particularly innovative as a psychomotor evaluation method (Ban, 2003). Similarly, in nursing education, the number of reports discussing the OSCE has increased since 2005 (Kajiwara \& Nakanishi, 2011). Such a tendency may have been derived from the definition of nursing abilities to be acquired through undergraduate courses by the Ministry of Education, Culture, Sports, Science, and Technology in 2004 (Ministry of Education, Culture, Sports, Science, and Technology, 2011). Previous studies examining the usefulness of the OSCE in nursing mainly reported its significance in: promoting students' autonomous learning and technical self-training to prepare for it (Takahashi, Asakawa, Numaguchi et al., 2009); clarifying points to be noted during clinical training (Uchida, Tsuchiya, Akahoshi et al., 2008); and facilitating the evaluation of the ability to accurately understand clients, as well as technical assessment from the viewpoint of individuals requiring support (Taga, Hinotsu, Fukushima et al., 2009). On the other hand, the OSCE has not yet been adopted as a common examination for all nursing universities due to challenges, such as the necessity of unifying evaluation criteria, clarifying objectivity and difficulty levels for goal-setting, and addressing personnel and cost-related issues (Kajiwara \& Nakanishi, 2011). Under such circumstances, our department was established in 2010, with the educational goal of helping students 'acquire practical nursing abilities to mentally and physically heal clients'. In 2015, 5 years after its establishment, we conducted a trial OSCE immediately before clinical training for third-year students.

This study aimed to clarify the effect of the OSCE to enhance nursing students' recognition of their own learning goals and motivation to learn in preparation for clinical training, using the ARCS Model developed by John M. Keller (Keller, 2010). The ARCS Model, consisting of 4 key components: <attention>, <relevance>, <confidence>, and $<$ satisfaction $>$, has already been used at some medical and nursing universities to evaluate educational programs and their effects to motivate students to learn (Taniguchi, Yagi \& Kabeyama, 2011; Muranaka, Kumagai, Hattori et al., 2011). 


\section{Subjects and Methods}

\section{Subjects and Procedures}

Questionnaires were conducted to 119 students in their third year as of 2015 were studied after OSCE was implemented. Using an anonymous, self-administered questionnaire, the students' attributes, frequency of reviewing their previous studies to prepare for the OSCE, duration of each review, and the effect of the OSCE to enhance their technical level and recognition of their own learning goals were examined. The questionnaire also contained statements, created by modifying the 5 subscales of the 4 ARCS components. Each statement was rated on a 4-point Likert scale. A space to freely describe overall impressions of the OSCE was also inserted.

\section{Data Collection}

To avoid obligating the students to participate in the study, the questionnaire and an explanatory document outlining the study were distributed to them by fourth-year students as volunteers in a different room than the examination venue. The students were asked to directly drop their responses into a collection box after filling out the questionnaire.

\section{Statistics analysis}

Responses to the questionnaire items were simply totaled, and ordinal scales for the modified ARCS items were quantified (-2 to 2) to calculate scores. Subsequently, the correlation between the effect of the OSCE to enhance students' recognition of their own learning goals and 4 ARCS components was analyzed to calculate Spearman's rank correlation coefficient $(\rho)$. Among the study items, those showing a markedly strong correlation, represented by $\rho>0.4$, were used as independent variables, and the effect of the OSCE to enhance students' recognition of their own learning goals was used as a dependent variable when performing multiple regression analysis (stepwise method). For analysis, the statistical analysis software SPSS Ver. 22.0 was used, with the significance level set at $\mathrm{p}<0.05$. The students' free descriptions were examined through word frequency analysis using Text Mining Studio Ver. 5.1 to extract the 10 most frequent words. Furthermore, dependency and topic analyses were performed to examine words showing dependency and co-occurrence relationships, respectively, with the most frequent word 'tension'.

\section{Ethical Considerations}

Prior to the study, the approval of the Ethics Committee of the Faculty of Health Science and Nursing, Juntendo University was obtained (approval number: 27-04). To prevent the identification of individuals, an anonymous, self-administered questionnaire was used. In addition, to avoid obligating the students to participate in the study, the 
questionnaire was distributed by fourth-year students as volunteers in a different room than the examination venue, asking respondents to directly drop their responses into a collection box after filling it out. The explanatory document outlining the study specified that preventive measures against the identification of individuals were adopted, and participation in the study was completely unrelated to academic achievements. The submission of each response was regarded as consent from a student.

\section{Results}

All of the 119 students taking the trial OSCE responded to the questionnaire (response rate: $100 \%)$. As for their attributes, there were 10 males (8.4\%) and 109 females (91.6\%), with a mean age of $20.53 \pm 0.68$. To prepare for the OSCE, $109(91.6 \%)$ had reviewed their previous studies. The mean total number of reviews was 4.67 (range: 1-20), and the mean duration of each review was $2.65(1-5)$ hours.

The students rated each statement to clarify the effect of the OSCE, as follows: [The OSCE has enhanced my technical level]: < Strongly agree $>: 9(7.6 \%),<$ Agree $>: 80$ (67.2\%), $<$ Disagree $>$ : $28(23.5 \%)$, and <Strongly disagree $>$ : $2(1.7 \%)$; more than $70 \%$ positively responded; and [The OSCE has led me to recognize my own learning goals]: < Strongly agree>: $73(61.4 \%),<$ Agree $>: 42(35.3 \%),<$ Disagree $>: ~ 3(2.5 \%)$, and $<$ Strongly disagree $>$ : $1(0.8 \%)$; more than $90 \%$ positively responded. Among the 4 ARCS components, $<$ satisfaction $>$ achieved the highest quantified score. Similarly, among the subscales, \{I want to review the items for which I had poor results in the OSCE\} achieved the highest quantified score (Table 1).

On the correlation analysis between the effect of the OSCE to enhance students' recognition of their own learning goals, which was positively rated by $90 \%$, and ARCS Model, all of the 4 components, <attention>, < relevance>, <confidence>, and $<$ satisfaction $>$, showed a strong correlation, with $r>0.2$. Among these, $<$ attention $>$ : $\{$ The OSCE has provided me with new insights\}, <confidence>: \{The OSCE has clarified my learning goals\} and \{The OSCE has enhanced my motivation to learn\}, and $<$ satisfaction >: \{I want to review the items for which I had poor results in the OSCE $\}$ and \{The OSCE has been useful to develop autonomous learning behavior\} showed a markedly strong correlation, with $r>0.4$ (Table 2). 
$<$ Table 1>Quantified Scores for Each Component of the ARCS Model (n=119)

\begin{tabular}{|c|c|c|}
\hline $\begin{array}{c}\text { ARCS } \\
\text { component }\end{array}$ & Statement & $\begin{array}{l}\text { Quantified } \\
\text { score }\end{array}$ \\
\hline \multirow[t]{6}{*}{$<$ Attention> } & $\begin{array}{l}\text { The OSCE has been helpful for the visualization of } \\
\text { clinical training. }\end{array}$ & .59 \\
\hline & $\begin{array}{l}\text { The OSCE has enhanced my interest in clinical } \\
\text { training. }\end{array}$ & .37 \\
\hline & $\begin{array}{l}\text { The OSCE has increased my curiosity about clinical } \\
\text { training. }\end{array}$ & -.18 \\
\hline & The OSCE has provided me with new insights. & 1.37 \\
\hline & I want to repeat the OSCE many times. & -.86 \\
\hline & Total & 1.25 \\
\hline \multirow[t]{6}{*}{$<$ Relevance $>$} & $\begin{array}{l}\text { The OSCE has made me feel familiar with clinical } \\
\text { training. }\end{array}$ & .14 \\
\hline & $\begin{array}{l}\text { I had prepared for the OSCE through autonomous } \\
\text { learning. }\end{array}$ & .97 \\
\hline & $\begin{array}{l}\text { I had prepared for the OSCE through learning focusing } \\
\text { on my strong points. }\end{array}$ & .18 \\
\hline & $\begin{array}{l}\text { I had prepared for the OSCE through elaborated or } \\
\text { repetitive learning. }\end{array}$ & 1.17 \\
\hline & $\begin{array}{l}\text { The OSCE has been helpful to understand the relevance } \\
\text { between knowledge and practical skills. }\end{array}$ & .53 \\
\hline & Total & 3.25 \\
\hline \multirow[t]{6}{*}{$<$ Confidence $>$} & The OSCE has clarified my learning goals. & 1.16 \\
\hline & The OSCE has contributed to my stable learning. & .55 \\
\hline & $\begin{array}{l}\text { I have become more confident through leaning to } \\
\text { prepare for the OSCE. }\end{array}$ & -.38 \\
\hline & It has been productive for me to take the OSCE. & .35 \\
\hline & The OSCE has enhanced my motivation to learn. & .79 \\
\hline & Total & 2.47 \\
\hline \multirow[t]{6}{*}{$<$ Satisfaction $>$} & The OSCE has stabilized my acquired knowledge. & .59 \\
\hline & Preparation for the OSCE has been enjoyable. & -.61 \\
\hline & $\begin{array}{l}\text { The OSCE has enhanced my preparedness for clinical } \\
\text { training. }\end{array}$ & .78 \\
\hline & $\begin{array}{l}\text { I want to review the items for which I had poor results } \\
\text { in the OSCE. }\end{array}$ & 1.61 \\
\hline & $\begin{array}{l}\text { The OSCE has been useful to develop autonomous } \\
\text { learning behavior. }\end{array}$ & 1.07 \\
\hline & Total & 3.44 \\
\hline
\end{tabular}


$<$ Table 2>Correlation between the Recognition of Learning Goals and Each Component of the ARCS Model $(n=119)$

\begin{tabular}{|c|c|c|}
\hline $\begin{array}{c}\text { ARCS } \\
\text { component }\end{array}$ & Statement & $\begin{array}{l}\text { Recognition of } \\
\text { learning goals }\end{array}$ \\
\hline \multirow[t]{4}{*}{$<$ Attention $>$} & $\begin{array}{l}\text { The OSCE has been helpful for the visualization } \\
\text { of clinical training. }\end{array}$ & $.341^{* *}$ \\
\hline & $\begin{array}{l}\text { The OSCE has enhanced my interest in clinical } \\
\text { training. }\end{array}$ & $.387 * *$ \\
\hline & $\begin{array}{l}\text { The OSCE has increased my curiosity about } \\
\text { clinical training. }\end{array}$ & $.392^{* *}$ \\
\hline & The OSCE has provided me with new insights. & $.449 * *$ \\
\hline \multirow[t]{4}{*}{$<$ Relevance $>$} & $\begin{array}{l}\text { The OSCE has made me feel familiar with clinical } \\
\text { training. }\end{array}$ & $.270^{* *}$ \\
\hline & $\begin{array}{l}\text { I had prepared for the OSCE through autonomous } \\
\text { learning. }\end{array}$ & $.210^{*}$ \\
\hline & $\begin{array}{l}\text { I had prepared for the OSCE through elaborated } \\
\text { learning. }\end{array}$ & $.269 * *$ \\
\hline & $\begin{array}{l}\text { The OSCE has been helpful to understand the } \\
\text { relevance between knowledge and practical skills. }\end{array}$ & $.371^{* *}$ \\
\hline \multirow[t]{5}{*}{$<$ Confidence> } & The OSCE has clarified my learning goals. & $.553^{* *}$ \\
\hline & The OSCE has contributed to my stable learning. & $.278^{* *}$ \\
\hline & $\begin{array}{l}\text { I have become more confident through learning to } \\
\text { prepare for the OSCE. }\end{array}$ & $.183^{*}$ \\
\hline & It has been productive for me to take the OSCE. & $.373^{* *}$ \\
\hline & The OSCE has enhanced my motivation to learn. & $.429 * *$ \\
\hline \multirow[t]{5}{*}{$<$ Satisfaction $>$} & The OSCE has stabilized my acquired knowledge. & $.279 * *$ \\
\hline & The OSCE has been enjoyable. & $.205^{*}$ \\
\hline & $\begin{array}{l}\text { The OSCE has enhanced my preparedness for } \\
\text { clinical training. }\end{array}$ & $.324^{* *}$ \\
\hline & $\begin{array}{l}\text { I want to review the items for which I had poor } \\
\text { results in the OSCE. }\end{array}$ & $.437^{* *}$ \\
\hline & $\begin{array}{l}\text { The OSCE has been useful to develop autonomous } \\
\text { learning behavior. }\end{array}$ & $.442^{* *}$ \\
\hline
\end{tabular}

$* p<0.05 \quad * * p<0.01$ 
Furthermore, on multiple regression analysis (stepwise method), with the 5 subscales showing a markedly strong correlation represented by $r>0.4$ as independent variables and the effect of the OSCE to enhance students' recognition of their own learning goals as a dependent variable, the following subscales were shown to influence such an effect: $<$ satisfaction $>$ : $\{$ I want to review the items for which I had poor results in the OSCE\}; and $<$ confidence>: \{The OSCE has clarified my learning goals\} and\{The OSCE has enhanced my motivation to learn\}. Among these, \{I want to review the items for which I had poor results in the OSCE \} showed a particularly high standardizing coefficient $(B=0.383)$ (Table 3). Through this analysis, the following regression formula was obtained: [Recognition of learning goals] $=0.409 \times<$ willingness to review $>+0.178 \times<$ clarified learning goals $>+0.146 \times<$ enhanced motivation to learn $>+0.551$.

$<$ Table 3>Multiple Regression Correlation between the Recognition of Learning Goals and Each Component of the ARCS Model $(n=119)$

\begin{tabular}{cc}
\hline & $\begin{array}{c}\text { Standardizing } \\
\text { coefficient }\end{array}$ \\
\hline I want to review the items for which I had poor results in the OSCE & $.383^{* *}$ \\
The OSCE has clarified my learning goals (<confidence $>)$ & $.219^{* *}$ \\
The OSCE has enhanced my motivation to learn $(<$ confidence $>)$ & $.207^{*}$ \\
\hline $\mathrm{R}^{2}$ (coefficient of determination) & .413 \\
Adjusted $\mathrm{R}^{2}$ (adjusted coefficient of determination) & .398 \\
F-value & $26.513^{* *}$ \\
\hline$* p<0.05 \quad * * p<0.01 \quad$ df (degree of freedom) & 3
\end{tabular}

On word frequency analysis, the word that most frequently appeared in the students' free descriptions was 'tension (48)', followed by 'think (30)', 'can do + cannot do (22)', 'training (20)', 'self-training (17)', 'feel (15)', 'good (14)', 'do (13)', 'goals (12)', and 'understand (10)', in this order. On dependency analysis to examine dependency relationships, 'tension' most frequently depended on the following combinations of words: 'tension - can do + unavailable (3)', 'tension - submit + cannot do (3)', 'training commute (3)', 'training - go (3)', 'dropping number - calculate (3)', 'mind - panic (3)', 'care do (2)', 'tension - good (2)', 'case - read (2)', and 'explanation - want (2)'. Similarly, on topic analysis to outline topics appearing throughout texts, and clarify the characteristics of sentences from the perspective of semantics, word networks were analyzed, focusing on the most frequent word 'tension'. The results revealed a co-occurrence relationship among 'tension', combinations/words connected to the former, such as 'review + want to 
do', 'do', 'go', 'experience', 'atmosphere', 'feel ', 'test', 'wrong', and 'situation', and 'training', to which the former and all of these combinations/words were connected (Figure 1).

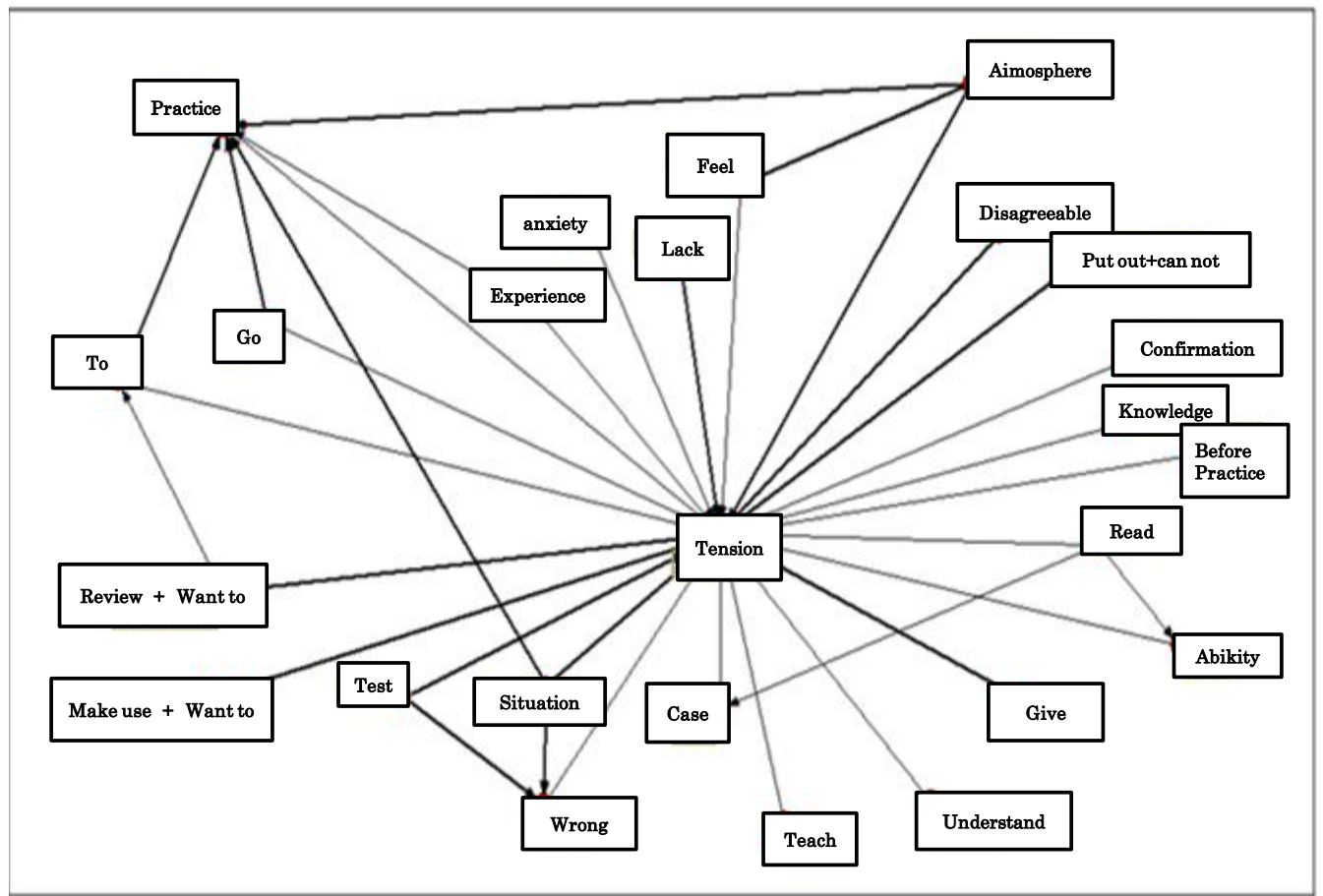

$<$ Figure 1> Word Network Graph

\section{Discussion}

More than $90 \%$ of the students had reviewed their previous studies to prepare for the trial OSCE, and the rates of positively rating the statements to clarify the effect of the OSCE to enhance students' technical level and recognition of their own learning goals exceeded 70 and $90 \%$, respectively. This is consistent with students' opinions regarding the OSCE collected in a previous study, such as (The OSCE has been useful for me to improve my own skills\} and \{I cannot use the most of my skills due to my insufficient technical level\} (Takahashi, Asakawa, Numaguchi, et al., 2009), which explain the significance of the examination from the viewpoint of students. Based on this, the OSCE as a process to prepare for clinical training may have provided the students with a more practical learning opportunity. In another previous study, the importance of the participation of nursing students and faculty members in practical lectures and pre-clinical training was noted (Matsunaga, Shinchi, Akinaga, et al., 2013).

In order to clarify the effect of the OSCE to motivate students to learn, it may be useful to refer to motivational concepts and theories that have been increasingly introduced to date, the latter of which are classified into 4 major categories: 1) those addressing genetic characteristics based on physiology and neurology, 2) those adopting behavioristic approaches, 3) expectancy-value theories, and 4) those focusing on feelings and emotions. 
Motivational theories and concepts have been reported to influence the level of effort to fulfill a purpose and the ability to maintain such effort until a successful outcome is achieved (J. M. Keller, 2010). Furthermore, the ARCS Model used in the present study to examine the effect of the OSCE to motivate students to learn is based on the Macro Model of Motivation and Performance, and it also functions as a system theory to explain relationships using the concept of input/process/output. Among the key components of the ARCS Model, <attention>, < relevance>, and <confidence> represent the input values of the OSCE as a process to prepare for clinical training. <Satisfaction>, the fourth component of the ARCS Model, depends on positive/negative emotions or attitudes students show toward their OSCE results as an output in comparison with a consequence of performance they expect after the process of making effort based on their recognition of the OSCE as a valuable method to prepare for clinical training. <Satisfaction> showed the highest quantified score of all components. Similarly, II want to review the items for which I had poor results in the OSCE\} showed the highest score of all subscales. Correlation and multiple regression analyses also confirmed that <satisfaction> and II want to review the items for which I had poor results in the OSCE\} most markedly influence the effect of the OSCE to enhance students' recognition of their learning goals. These results indicate that the students accepted their OSCE results, with positive emotions and attitudes, and such acceptance resulted in the high willingness to review observed in the subscale of <satisfaction> as an output, supporting the effectiveness of the examination to motivate students to learn. With respect to students' willingness to review, representing their <satisfaction>, a previous study examining the relationship between OSCE examinees' psychological responses and motivation to learn reported that those with higher achievement levels were not motivated to re-learn, and positive feedback simply enhanced their sense of security, not necessarily motivating them to re-learn (Fujii, Shindo, Uchida et al., 2012). At this point, <satisfaction>, which was shown to most markedly influence the effect of the OSCE to motivate students to learn, may be different from psychological responses such as senses of accomplishment and security.

On analyzing the students' free descriptions to identify psychological factors that confirm the effect of the OSCE to motivate students to learn, the most frequent word was 'tension'. When focusing on the word 'tension' to discuss the students' psychological responses to the OSCE, it is noted that individuals attach importance to being favorably evaluated by others, and 3 factors: evaluation apprehension, impression management, and self-presentation promote self-attention, as explained by the Objective Self-Awareness Theory (Oshimi, 1990). In the OSCE, students are evaluated by 3 parties: faculty members, examiners, and simulated patients. Therefore, in the present study, these factors may have been promoted in the students being evaluated by others in an environment similar to the clinical setting, consequently increasing their 'tension'. Conversely, this word most frequently appeared in their free descriptions, indicating that 
self-attention was promoted in the majority. Promoted self-attention has been reported to lead to 2 patterns of self-discrepancy: 1) evaluating real self based on an intrinsic standard of value; developing ideal-real self-discrepancy; intensifying the senses of worthlessness and discomfort; and distracting one's attention to environments to ignore such discrepancy, in order to avoid or escape from uncomfortable feelings (distraction or avoidance of self-attention); and 2) being motivated to improve real self to meet the standard of value (reduced self-discrepancy) (Oshimi,1990). On word network analysis focusing on 'tension', the students showed positive responses representing their enhanced motivation to learn, as well as negative ones, such as 'do not want' and 'submit + cannot do'. 'Tension' was connected to 'review + want to do', 'do', 'go', 'atmosphere', 'feel ', 'experience', and 'situation', and these combinations/words were connected to 'training'. Such a co-occurrence relationship suggests that the students' willingness to review their previous studies and preparedness for clinical training were promoted. Although the object is unclear, the combination of words: 'make the most of + want to do' may also explain the students' desire to step forward based on their experience as a positive outcome of the OSCE that reduces ideal-real self-discrepancy. On examining the results of dependency analysis and factors influencing the effect of the OSCE to enhance students' recognition of their own learning goals, 'review + want to do' depended on \{I want to review the items for which I had poor results in the OSCE), and 'review + want to do' and 'make the most of + want to do' depended on (The OSCE has enhanced my motivation to learn\} and \{The OSCE has clarified my learning goals\}, without inconsistency. The students' overall impressions of the OSCE also supported its effect to motivate students to learn in preparation for clinical training. Their willingness to review their previous studies, representing their <satisfaction>, was shown to most markedly influence such an effect, and 'tension' as a psychological response may explain their situation.

A trial use of the OSCE, which is being adopted as a common examination for medical and dental education, provided the nursing students with a more practical learning opportunity. On examining its effect to motivate students to learn in preparation for clinical training, the willingness of review of previous studies as a subscale of $<$ satisfaction $>$ most markedly influenced such an effect of all components of the ARCS Model. The results support the effectiveness of the OSCE to motivate students to learn, while suggesting that 'tension' as a psychological response explains their situation in terms of reduced ideal-real self-discrepancy.

\section{Acknowledgment}

I would like to express my gratitude to everyone, students, faculty and staff of simulated patients who cooperated in implementing OSCE. 


\section{References}

1) Keiko NAKAMURA (2014) Nursing OSCE, Medical Friend Co. Ltd.

2) Shintaro BAN (2003) Objective Structured Clinical Examination (OSCE) - A New Development in Assessing Clinical Competence -, Medical Education, 26(3), 157-162.

3) Rie KAJIWARA \& Junko NAKANISHI (2011) Literature Review of the Utilization of Objective Structured Clinical Examinations in Undergraduate Nursing Education, Bulletin Ehime Prefectural University Of Health Sciences 8(1), 35-41.

4) Ministry of Education, Culture, Sports, Science and Technology (2011) Final Report of the Review Meeting for the Development of Nursing Human Resources at Universities.

5) Yuki TAKAHASHI, Kazumi ASAKAWA, Chieko NUMAGUCHI, Yoko KURODA, Kayoko ITO, Chie KONDO et al., (2009) Evaluation of OSCE conducted with teachers from all fields: OSCE in view of the recognition of nursing university students, Acta Scientiarvm Valetvdinis Universitatis Praefectvralis Ibarakiensis 14, 1-10.

6) Rinko UCHIDA, Yachiyo TSUCHIYA, Nariko AKAHOSHI, Miyuki YAMADA, Shoko OGATA \& Shoko OKU (2008) On trial of Objective Structured Clinical Examination in Adult Nursing, The South Kyusyu journal of nursing, 6(1), 55-61.

7) Masae TAGA, Junko HINOTSU, Mari FUKUSHIMA \& Harumi Ota (2009) Significance of Trial Objective Structured Clinical Examinations (OSCEs) from the Viewpoint of Students, SCU Journal of Design \& Nursing 3(1), 27-34.

8) John M. KELLER (2010) Motivational Design for Learning Performance. The ARCS Model Approach, Kitaoji Shobo.

9) Hatsumi TANIGUCHI, Keiko YAGI \& Kiyoko KABEYAMA (2011) An Approach to Improve Situation Assessment using Simulation Methods, and the Evaluation of Midwifery Students' Learning Motivation, Annual reports of School of Health Sciences Faculty of Medicine, Kyoto University, Health Sciences, 7, 43-47. doi: 10.14989/173385.

10) Yoko MURANAKA, Tamaki KUMAGAI, Keiko HATTORI, Sayuri SUZUKI \& Shino SASAKI (2011) Description and Evaluation of an ICT-based Instruction System in Nursing Skill Classes, Juntendo University Faculty of Healthcare and Nursing Journal of Health Care and Nursing, (7)1, 53-58.

11) Hitomi MATSUNAGA, Koichi SHINCHI, Kazuyuki AKINAGA \& Setsuko UMEZAKI (2013) Recognition of the Necessity of Practical Disaster Nursing Education among Nursing Teachers in Japan, Asian Journal of Human Services, 4, 30-39. 
12) Mizue FUJII, Yukari SHINDO, Masako UCHIDA, Michiko MIYAZAKI, Natsuyo ONO, Mitsuko SHIMIZU, et al., (2012) Examinees' Psychological Responses to the Nursing OSCE, Their Relationship with Motivation to Learn, and Related Challenges - Results of a Questionnaire Survey Involving Students, Japanese Nursing Association Anthology, 42, 10-13.

13) Teruo OSHIMI (1990) Hiyoshi Nakamura (edition). Stage of Self-Attention Sociopsychology of Self-Process, University of Tokyo Press,21-65. 
- Editorial Board -

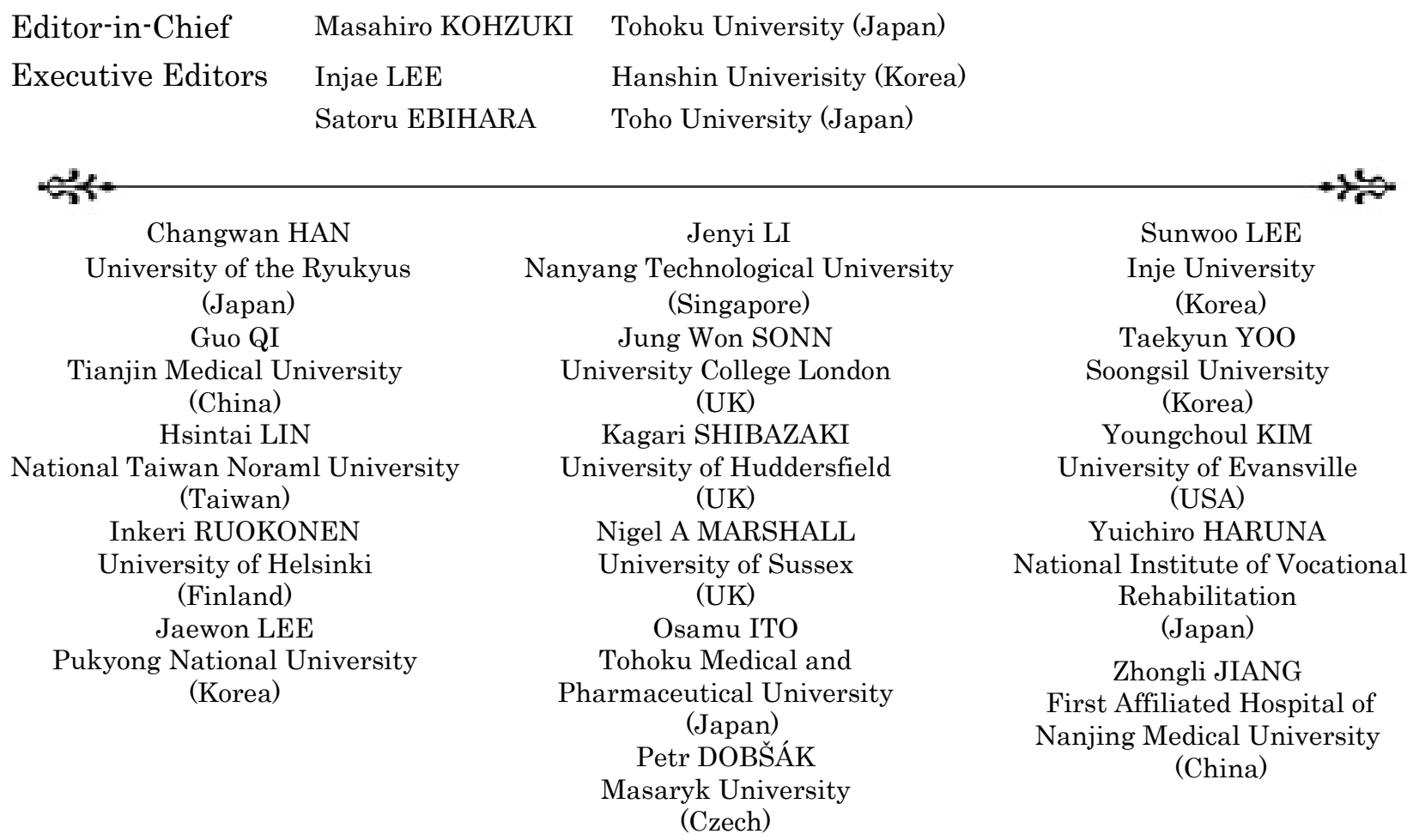

Editorial Staff

- Editorial

Assistants
Aiko KOHARA

Marcus Eije Zantere

Moonjung KIM
University of the Ryukyus (Japan)

University of Gothenburg (Sweden)

Korea Labor Force Development Institute for the aged (Korea)

Natsuki YANO

Tohoku University / University of the Ryukyus (Japan)

\section{Asian Journal of Human Services VOL.15 Ocober 2018}

(C) 2018 Asian Society of Human Services

$\begin{array}{ll}\text { Editor-in-Chief } & \text { Masahiro KOHZUKI } \\ \text { Presidents } & \text { Masahiro KOHZUKI } \cdot \text { Sunwoo LEE } \\ \text { Publisher } & \text { Asian Society of Human Services } \\ & \text { Faculty of Education, University of the Ryukyus, 1 Senbaru, Nishihara, Nakagami, Okinawa, Japan } \\ & \text { FAX: +81-098-895-8420 E-mail: ashs201091@gmail.com }\end{array}$

Production Asian Society of Human Services Press

Faculty of Education, University of the Ryukyus, 1 Senbaru, Nishihara, Nakagami, Okinawa, Japan FAX: +81-098-895-8420 E-mail: ashs201091@gmail.com 


\section{Asian Journal of Human Services \\ VOL.15 October 2018 \\ CONTENTS}

\section{ORIGINAL ARTICLES}

Using Videos to Analyze the Effectiveness of START Education for Japanese Nursing Students

Kazuyuki AKINAGA et al., 1

Effects of the OSCE to Motivate Students to Learn Before Clinical Practice

Yuko FUJIO et al., 13

The Current Status and Its Implications of Public-Private Partnerships for Official Development

Assistance in Korea: Focusing on Disability-Inclusive Development Cooperation

Juhee HWANG et al., 25

Effects of a Structured 8-week Nordic Walking Exercise Program on Physical Fitness in the Japanese Elderly

Study of "Individuality" on Nursing Care Job

Kimiko YAMAMOTO et al., 38

Kimiko YAMAMOTO et al., 52

\section{SHORT PAPERS}

A Comparison of the Factor Structure of the Self-Harm Antipathy Scale and related Demographic Characteristics between Korea and Japan

Yoshimi AOKI et al., 66 Issues of Specific Educational Curriculum Development for Resource Rooms and Special Needs Classes in Japanese High Schools

Mitsuyo SHIMOJO et al., 76

\section{REVIEW ARTICLES}

Importance of Physical Activity and $\dot{\mathrm{V}}_{2}$ max: Five Major Determinants of $\dot{\mathrm{V}}_{2} \max$

Masahiro KOHZUKI et al., 85

Importance of Physical Exercise in Oldest-old Adults: A Literature Review Study

Chaeyoon $\mathrm{CHO}$ et al., 93

Published by

Asian Society of Human Services

Okinawa, Japan 